\title{
I Have a Dream and it's Green
}

\author{
Chandramohan D* \\ Department of Mechanical Engineering, India \\ *Corresponding author: Chandramohan D, Department of Mechanical Engineering, Tamil Nadu 603103, India
}

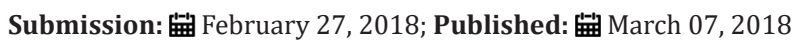

\section{Opinion}

Increased environmental awareness and societal needs serve as a catalyst for developing new eco-friendly materials like green composites. Today fibre composites are replacing traditional petroleum based products such as resins in thermo-set plastics, which are toxic and non-biodegradable. Composites with natural fibres have the potential to be attractive alternative to synthetic fibre composites. Green composites combine plant fibres with natural oil resins like soybean-oil to create natural composite materials. In the case of "Green" composites, natural fibres derived from bamboo, hemp, or flax are being added to biodegradable resins, to reinforce polymer matrix materials and improve the mechanical properties of resulting composites. In recent years there has been considerable interest in using natural plant fibres as reinforcements for plastics. The motivation includes cost, performance enhancement, weight reduction, and environment concerns. High performance flax fibre could potentially substitute for glass or carbon fibres as reinforcements for plastics. The natural fibre-reinforced polymer composites are growing rapidly due to many advantages over traditional composites. Fibrereinforced composites have been used for many applications such as aerospace, automotive parts from sporting goods, circuit boards, etc. Most commercially produced fibre-reinforced composites use petroleum based or synthetic fibres and resins that are nondegradable. Goals are to develop fully degradable, environmentfriendly ("Green") composites using cellulose fibres, yarns and/or fabrics as reinforcement. Biodegradable polymers produced from renewable resources such as plants, animals and microbes through biochemical reactions offer a convenient and environment-friendly solution to the problem of plastic waste. Composite materials are engineered materials made from two or more constituent materials with significantly different physical or chemical properties and which remain separate and distinct on a macroscopic level within the finished structure. Green composite combines plant fibres with natural resins to create natural composite materials. Biomaterial composites are made from hemp, kenaf, sisal, soybean, etc. Natural fibres are emerging as low cost, lightweight and apparently environmentally superior alternative to synthetic fibres. The resins and fibres used in the green composites are biodegradable, when they dumped, decomposed by the action of microorganisms. They are converted into the form of $\mathrm{H}_{2} \mathrm{O}$ and $\mathrm{CO}_{2}$. These $\mathrm{H}_{2} \mathrm{O}$ and $\mathrm{CO}_{2}$ are absorbed into the plant systems. Green materials are the wave of the future. There is an immense opportunity in developing new bio-based products, but the real challenge is to design sustainable bio-based products. New environmental regulations and societal concern have triggered the search for new products and processes that are compatible with the environment. The major limitations of present biodegradable polymers are their high cost. Bio-composites are emerging as a realistic alternative to glass-reinforced composites. Because bio-composites are derived from renewable resources, material costs can be markedly reduced with their large-scale usage. Natural fibres are biodegradable, but renewable resource-based bio-plastics can be designed to be either biodegradable or not according to the specific demands of a given application. Their unique balance of properties would open up new market development opportunities for bio-composites in the $21^{\text {st }}$ century green materials world. It can be concluded that green composites is an essential guide for agricultural crop producers, government agricultural departments, automotive companies, composite producers and material scientists, all dedicated to the promotion and practice of eco-friendly materials and production methods. The natural fibre composites or green composites can be effectively used as a material for structural, automotive, medical and electronic applications. Natural/Bio-fibre composites (green composites) are emerging as a viable alternative to glass fibre reinforced composites especially in automotive and building product applications. 
Creative Commons Attribution 4.0 International License

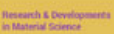

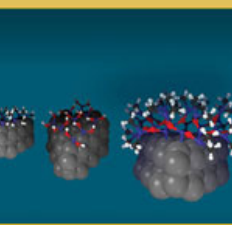

\section{Research \& Development in Material Science}

\section{Benefits of Publishing with us}

- High-level peer review and editorial services

- Freely accessible online immediately upon publication

- Authors retain the copyright to their work

- Licensing it under a Creative Commons license

- Visibility through different online platforms 